\author{
APRESENTAÇÃO \\ DOSSIÊ TEMÁTICO
}

\title{
POLÍTICAS LINGUÍSTICAS OFICIAIS E OFICIOSAS: DA BNCC AO ESCOLA SEM PARTIDO
}

\author{
Juliana Zeggio MARTINEZ \\ Universidade Federal do Paraná \\ Núcleo de Assessoria Pedagógica \\ jumartinez@ufpr.br
}

Ana Paula Marques BEATO-CANATO

Universidade Federal do Paraná Núcleo de Assessoria Pedagógica anabeatocanato@gmail.com

\author{
Alessandra Coutinho FERNANDES \\ Universidade Federal do Paraná \\ Núcleo de Assessoria Pedagógica \\ alessandrawiggers@gmail.com
}

Pensar, analisar e debater políticas linguísticas e educacionais, oficiais e oficiosas, como a Base Nacional Comum Curricular (BNCC) e o Movimento Escola sem Partido (MESP) nos levam a entender que nosso desafio nesta tarefa não está naquilo que é aparentemente visível em cada uma dessas propostas. Nesse sentido, buscamos destrinchar e problematizar as intenções e os efeitos no mundo das políticas mencionadas, uma vez que elas não são fatos, mas processos em construção social. Vale ressaltar que a BNCC é uma política oficial, porque foi construída e promulgada oficialmente; o MESP não é, mas pode ser compreendido como uma política oficiosa, porque tem sido produzida por uma organização não oficial, sem caráter normativo, e tem influenciado demasiadamente políticas oficiais e práticas pedagógicas. 
Assim, a capa que abre este dossiê nos remete a ideia de processo e construção e nos leva a considerar um infinito conjunto de linhas entrelaçadas, como em uma trama, onde uma linha nos leva a outra linha num processo ad infinitum de construção de sentidos, de desafios, de possibilidades, de potencialidades. O vermelho do quadro nos remete à compreensão da vida que pulsa, como algo que não é dado, portanto, não se encontra em estagnação. Essa vida que pulsa reside, em nossa compreensão, na escola, na sociedade, no mundo, nas ruas, nos sonhos, em nossas casas, em tudo onde há existência. A cor vermelha nos leva a pensar nas batidas de um coração, que pulsa e pulsa e pulsa; e não pode parar de pulsar, pois não pulsar significaria sua morte. Como um eletrocardiograma nos mostra, o equilíbrio da vida não está na linha reta, mas em seus altos e baixos, em sua constante busca por aquilo que entende ser o seu equilíbrio, num processo constante de abrir e fechar, de significar e ressignificar.

Este dossiê surgiu da necessidade de pulsar, de pulsar por outros e novos sentidos, de promover diálogo entre a Educação Básica e a Educação Superior, entre a universidade e a sociedade em geral, num debate mais assertivo a respeito do atual cenário social, histórico e político em que estamos imersas/os e que se mostra desfavorável a ações educativas críticas. Entendemos que é preciso buscar formas de dialogar com outros setores da sociedade para que o trabalho que realizamos nas escolas seja melhor compreendido e significativo, e discursos sem compromisso ético com a realidade sejam problematizados e mitigados. Desse modo, este dossiê tem por objetivo abrir espaço para ampliarmos a discussão sobre políticas públicas que afetam a educação, que afetam nossa existência e convivência, bem como trazem implicações à educação linguística no Brasil na contemporaneidade. Assim como as batidas de um coração, entendemos que mesmo com a imposição de documentos como a BNCC e de movimentos como o MESP, que clamam por uma organização normativa e hegemônica da vida, a potencialidade criativa que reside nas escolas, nos saberes e nos sujeitos da educação está no caos que faz surgir o novo todos os dias.

É na multiplicidade de contextos, práticas, discursos e análises que se encontram as duas entrevistas e os quinze artigos que compõem este dossiê. Cada autor e autora deste volume contribui para este exercício de reflexão no qual o dissenso e o caos não deixam de existir e exigem de nós engajamento, criticidade, ação. Nessa multiplicidade, as/os 
participantes deste dossiê nos ajudam a ampliar os espectros de discussão e de análise sobre a questão das políticas linguísticas - oficiais ou oficiosas, como macro ou micropolíticas, no texto da legislação ou no chão da escola. As autoras e autores nos presenteiam aqui com suas pesquisas em diferentes cenários, espaços espectros. Temos artigos que se voltam a discussões sobre a questão das línguas (Portuguesa, Inglesa, Espanhola, Francesa, Libras) na BNCC; outros tratam do estatuto das línguas (se estrangeira, adicional, materna, não materna, franca, de fronteira, etc.); e, outros ainda, analisam silenciamentos, resistências, omissões, ausências e/ou apagamentos de línguas, saberes e subjetividades nas políticas que analisam. Há artigos também que buscam pensar a BNCC nos diferentes segmentos educacionais, como a Educação Infantil, o Ensino Fundamental, o Ensino Médio, o Ensino Médio Integrado, bem como a Educação Profissional e Tecnológica de Nível Médio. Há ainda artigos que discutem a relação entre a BNCC e o MESP e/ou analisam as próprias ações promovidas pelo MESP, nos oportunizando diferentes reflexões sobre os impactos de ambas as políticas na atualidade. Outras temáticas atravessadas pela pesquisa no campo das políticas linguísticas pautam-se em conceitos mais amplos, como ideologia, globalização, neoliberalismo, direitos humanos, etc., e/ou conceitos voltados à educação linguística, como os gêneros discursivos, os letramentos, as práticas de escrita e oralidade na escola. Além disso, o dossiê nos traz a oportunidade de reflexão sobre a importância da formação de professores na área de estudos da linguagem.

Nossa primeira entrevistada, professora Mônica Ribeiro da Silva, é docente e pesquisadora no Setor de Educação da Universidade Federal do Paraná (UFPR), onde atua no campo dos estudos sobre currículo e políticas curriculares. Em sua entrevista, intitulada Faz sentido uma Base Nacional Comum Curricular?, aprendemos sobre sua participação ativa e incisiva em movimentos nacionais em defesa da educação pública. A pesquisadora nos ajuda a compreender a lacuna que existe entre as/os formuladoras/es de políticas educacionais e as realidades das escolas e/ou dos contextos educacionais Brasil afora, nos levando a pensar sobre a função social de políticas educacionais, e, especialmente, da educação que existe para muito além dos códigos da BNCC.

A segunda entrevista, intitulada No amplo contexto da Política de Estado para a Educação Brasileira: a BNCC sob os holofotes, nos foi concedida pela professora Eliana 
Santiago Gonçalves Edmundo, professora do quadro próprio do magistério do Estado do Paraná (SEED-PR) com vasta experiência na Educação Básica, incluindo desde a sala de aula até sua participação em secretarias e núcleos regionais de educação. Em sua entrevista, a pesquisadora traça um panorama das políticas que analisa a fim de buscar paralelos entre a BNCC e outras políticas, normativas e vigentes na atual legislação, nos levando a refletir acerca do cenário que permitiu com que a BNCC se instalasse.

Em relação aos artigos, o primeiro deles, intitulado Desafios no ensino de línguas na contemporaneidade: da BNCC ao Escola sem Partido, foi escrito por nós, organizadoras deste dossiê - Ana Paula Marques Beato-Canato (UFPR), Juliana Zeggio Martinez (UFPR) e Alessandra Coutinho Fernandes (UFPR). Em nosso texto, relatamos como surgiram nossas análises sobre a aproximação que buscamos fazer entre a BNCC e o MESP, e mencionamos, brevemente, o curso de extensão que oferecemos na UFPR com o intuito de problematizar possíveis implicações dessas políticas no processo de educação linguística. Discutimos também as implicações educacionais que percebemos nessas duas propostas e como ambas se relacionam com a sociedade brasileira e a globalização neoliberal; finalizamos enfatizando a importância da formação de professoras/es de línguas na atualidade.

Em Ideologias linguísticas: uma breve análise da BNCC, segundo artigo deste dossiê, Alexandra Nunes Santana (UEPG) desenvolve uma análise sobre as ideologias linguísticas atreladas à disciplina de Língua Portuguesa na BNCC, conectando língua e sociedade à luz dos estudos do Círculo de Bakhtin e das contribuições da Sociolinguística. De acordo com a pesquisadora, em cenários como este que estamos vivendo a partir da construção de políticas como a BNCC, é necessário que o/a professor/a esteja atento/a à concepção de linguagem que informa documentos educacionais e que, portanto, acarretam implicações ao ensino, no caso aqui, de Língua Portuguesa.

Políticas linguísticas para línguas adicionais na BNCC: contribuições para a formação de professores, terceiro artigo do dossiê, foi escrito por Marcela Dezotti Cândido (UFMG), Camila de Souza Santos (UFMG) e Silvana Maria Mamani (UFG). Em uma análise a partir das orientações elaboradas para as duas séries finais do Ensino Fundamental na BNCC, problematizando os conceitos de língua adicional e de competência tecnológica, as autoras concluem que a BNCC carece de aprofundamento 
teórico acerca desses conceitos e isso gera uma demanda maior na formação docente para preencher as lacunas encontradas.

Claudemir Sousa (UNESP), em seu artigo As contribuições da BNCC para as Práticas de Linguagem: mapeando gêneros discursivos multissemióticos, também analisa as potencialidades do ensino das práticas de linguagem em Língua Portuguesa na BNCC, enfatizando a importância da interação, da colaboração e do dialogismo. O autor destaca a integração das práticas de leitura, escrita e escuta em textos multissemióticos e a utilização de diferentes mídias dentro e fora das escolas. Para que tal proposta se efetive, o autor aponta a necessidade da disponibilidade de recursos na escola e também enfatiza a formação de professores/as em relação aos novos conceitos no campo dos estudos da linguagem para que um trabalho significativo tenha espaço nas escolas.

No quinto texto do dossiê, De língua estrangeira à língua franca e os paradoxos in-between: (tensionando) o ensino de língua inglesa à luz da BNCC, Juliana Silva Santana (SEED-BA) e Felipe Flores Kupske (UFBA) investigam algumas das mudanças na redação do texto do componente de Língua Inglesa na BNCC, na passagem de sua segunda para terceira versão. Em uma leitura analítica e reflexiva, a autora e o autor problematizam, não apenas a exclusão de outras línguas estrangeiras na BNCC, mas os paradigmas que informam o inglês como língua franca no documento, pautados no desenvolvimento de competências por vezes estruturais, como a ênfase na gramática e na pronúncia, em detrimento à inteligibilidade e à variação linguística.

Em Quando Políticas de Resistência se transformam em Políticas Linguísticas oficiais: o Espanhol no Nordeste Brasileiro, o pesquisador José Veranildo Lopes da Costa Júnior (UERN) e a pesquisadora Tatiana Lourenço de Carvalho (UERN) problematizam o processo pelo qual políticas de resistência se transformam em políticas linguísticas oficiais. A discussão e análise propostas no artigo tratam do ensino da Língua Espanhola no Nordeste do Brasil, sob a perspectiva das micropolíticas que se opõem à revogação da Lei Nacional $n^{\circ} 11.161 / 2005$. O autor e a autora apontam que, no caso do ensino de espanhol, o movimento de resistência vêm se tornando uma política oficial e garantindo a presença da Língua Espanhola nos currículos estaduais e municipais de educação. 
Marcella dos Santos Abreu (USP), em Silêncio e resistência: as línguas na escola em contextos de permanentes retrocessos, sétimo artigo deste dossiê, discute políticas linguísticas no Brasil a partir de registros do ensino de francês; sua análise perpassa o período da ditadura militar e culmina no momento mais recente de publicação da BNCC e da tramitação do Projeto de Lei Escola sem Partido. A autora destaca que há um recorrente silenciamento por parte de estudantes e professoras/es em seus territórios de aprendizagem, bem como um processo de negligência em relação a políticas comprometidas com o plurilinguismo nos currículos brasileiros. Consequentemente, a seu ver, este movimento de retrocesso produz o apagamento de práticas e saberes relacionados a experiências com línguas na escola.

\section{Rafaela Cristina Oliveira de Andrade (UFPB) e Cynthia Israelly Barbalho} Dionísio (UFPB) participam deste dossiê trazendo contribuições sobre a educação em Libras no oitavo artigo. Em Política Linguística oficial para a Educação em Libras no Estado de Pernambuco: um panorama de duas décadas (1999-2019), as pesquisadoras evidenciam que o Estado de Pernambuco tem contribuído para um processo dinâmico e interativo na construção de políticas oficiais voltados ao ensino-aprendizagem de Libras, fortalecendo a Libras no sistema educacional do Estado. De acordo com as autoras, as práticas locais, entretanto, ainda parecem distantes da legislação, o que exige esforços por parte das/os agentes envolvidas/os com o contexto para que tais políticas se traduzam na prática.

As autoras Juliana Reichert Assunção Tonelli (UEL) e Paula Aparecida Avila (Colégio Estadual Odete Borges Botelho), em A inserção de Línguas Estrangeiras nos anos iniciais de escolarização e a Base Nacional Comum Curricular: silenciamento inocente ou omissão proposital, trazem uma reflexão para o campo das políticas linguísticas sobre a (não) inserção do ensino de línguas estrangeiras na Educação Infantil e no Ensino Fundamental I. Para as pesquisadoras, há um processo de ausência de políticas oficiais que precisa ser problematizado, pois reflete a omissão por parte do Estado, mesmo não impedindo iniciativas locais de emergirem.

Ana Paula da Silva (UEL) e Ana Lúcia de Campos Almeida (UEL), no décimo artigo do dossiê, intitulado $O$ trabalho com projetos de letramento para o ensino crítico de língua materna, apresentam e discutem uma proposta de ensino de Língua Portuguesa por 
meio de projetos de letramento. Pautadas em uma perspectiva crítica da linguagem, as autoras defendem que a educação escolar deve promover a ampliação dos conhecimentos dos/das estudantes e garantir espaços educacionais para que possam posicionar-se acerca de valores socialmente estabelecidos e das transformações sociais necessárias.

No artigo seguinte, Bruna Elisa Frazatto (UNICAMP) engaja-se na análise de políticas linguísticas no contexto da internacionalização na Educação Superior, que, segundo a autora, trata-se de um contexto educacional no qual mecanismos de políticas linguísticas são criados e efetivados. Em Português como língua adicional no programa Idiomas sem Fronteiras na Unicamp: internacionalização e políticas linguísticas em foco, a pesquisadora analisa macro e micropolíticas linguísticas, discutindo a necessidade de se pensar nas políticas em contextos locais para que os propósitos da educação, e, no caso aqui da internacionalização, promovam trocas e cooperações sem servir à economia global do conhecimento.

Jaqueline Gomes dos Santos Teles (UFS), em seu texto A redação do Enem entre as políticas oficiais e oficiosas: o lugar dos direitos humanos, décimo segundo artigo deste dossiê, sistematiza argumentos que sustentam políticas, oficiais e oficiosas, no que diz respeito aos Direitos Humanos no âmbito da prova de redação do Enem. Segundo a autora, há uma tensão entre tais políticas; enquanto as oficiais consideram a função educacional da escola e o respeito aos Direitos Humanos, as oficiosas, a partir da organização e articulação de movimentos como o Escola sem Partido, ameaçam a concepção de educação cidadã.

\section{Daniele de Oliveira Moreira Barbosa (UFMS) e Daniela Sayuri Kawamoto} Kanashiro (UFMS), no décimo terceiro texto do dossiê, intitulado A reforma do Ensino Médio nas trilhas neoliberais, analisam algumas regulamentações estabelecidas na Reforma do Ensino Médio que acabam por alterar a Lei de Diretrizes e Bases da Educação (LDB - no 9.394/1996). A discussão proposta pelas autoras pauta-se no atual contexto neoliberal, nos desafios da formação docente e em princípios da educação linguística, a fim de investigar os impactos de tais mudanças na legislação para os anos finais da Educação Básica.

No penúltimo texto deste volume, em Políticas Linguísticas para o Ensino Médio Integrado: a situação das línguas adicionais, David José de Andrade Silva (IFPR - 
Campus Jacarezinho) investiga os efeitos das legislações concernentes às línguas adicionais para a Educação Profissional e Tecnológica, em especial para o Ensino Médio Integrado. O pesquisador enfatiza a importância de acompanhar e discutir criticamente os efeitos das decisões governamentais, no que se refere à questão das línguas, sobre os diversos níveis e modalidades da educação brasileira. Segundo o autor, o Ensino Médio Integrado não possui uma política linguística legalmente consistente, o que acaba por enfraquecer seu planejamento curricular.

Para finalizar, Verônica Ventorini Ferreira (UNISINOS) e Berenice Corsetti (UNISINOS), em A linguagem do Movimento Escola sem Partido: ideologia, doutrinação e neutralidade, analisam escritos das seções do site oficial do MESP por meio de um mapeamento e de significados historicamente atribuídos aos termos - ideologia, doutrinação e neutralidade. Segundo as autoras, a história da educação brasileira pauta-se no tensionamento entre posicionamentos mais conservadores e mais progressistas; e, neste momento, o MESP representa o conservadorismo no campo da educação de forma mais incisiva, pois agrega pessoas, dissemina o terror entre professoras/es e estudantes, forma opiniões e busca consolidar políticas para a educação.

Esperamos que a leitura dos artigos faça o coração de vocês, leitoras e leitores, pulsar e, assim, contribua para a reflexão sobre a relevância da pesquisa e da discussão no campo das políticas linguísticas, que afetam nosso cotidiano, nossas escolas, nossa profissão como professoras/es, nossa vida e existência. Agradecemos imensamente a participação das/os autoras/os pelo interesse na Revista X e por compartilharem neste dossiê resultados de suas pesquisas e estudos.

As Organizadoras. 